\title{
Erratum: Estimates for secondary electron emission and desorption yields in grazing collisions of gold ions with beam pipes in the BNL Relativistic Heavy Ion Collider: Proposed mitigation [Phys. Rev. ST Accel. Beams 7, 093201 (2004)]
}

\author{
P. Thieberger, W. Fischer, H. Hseuh, V. Ptitsyn, L. P. Snydstrup, D. Trbojevic, and S. Y. Zhang \\ (Received 25 October 2004; published 17 November 2004; publisher error corrected 18 November 2004) \\ DOI: $10.1103 /$ PhysRevSTAB.7.119901 \\ PACS numbers: 29.20.Dh, 29.20.Lq, 99.10.Cd
}

We are grateful to Edgar Mahner for pointing out that desorption yield information we obtained from Refs. [10] and [11] of the original paper was quoted incorrectly. Regarding charge-state dependence, the value relevant to our work is a factor of $\sim 3$ desorption yield increase between charge state $27+$ and $53+$ for $4.2 \mathrm{MeV} / \mathrm{amu}$ lead ions at near grazing incidence on stainless steel. For the desorption they measured with $158 \mathrm{GeV} / \mathrm{amu}$ In $49+$ incident on stainless steel at $35 \mathrm{mrad}$, the correct yield is $4 \times 10^{4}$ molecules per ion. Thus, our very rough $1 \mathrm{mrad}$ desorption yield estimate for $10 \mathrm{GeV} / \mathrm{amu}$ Au79+ incident on stainless steel with the surface roughness of the RHIC beam pipes is reduced from $\sim 10^{7}$ to $\sim 2 \times 10^{6}$. Most of the paper deals with secondary electron yields, and none of the other estimates or conclusions are affected. 